\title{
Potential Hazard Map for Snow Disaster Prevention Using GIS-Based Weighted Linear Combination Analysis and Remote Sensing Techniques: A Case Study in Northern Xinjiang, China
}

\author{
Gulijianati Abake1, Ahmad Al-Hanbali², Bayan Alsaaideh², Ryutaro Tateishi ${ }^{2}$ \\ ${ }^{1}$ Graduate School of Science, Chiba University, Chiba, Japan \\ ${ }^{2}$ Center for Environmental Remote Sensing, Chiba University, Chiba, Japan \\ Email: hanix009@yahoo.com, ahmadhanb@yahoo.com, bayansaideh@gmail.com, tateishi@faculty.chiba-u.jp
}

Received 24 October 2014; revised 24 November 2014; accepted 23 December 2014

Copyright (C) 2014 by authors and Scientific Research Publishing Inc.

This work is licensed under the Creative Commons Attribution International License (CC BY). http://creativecommons.org/licenses/by/4.0/

(c) (i) Open Access

\begin{abstract}
Snow disaster is one of the top ten natural disasters worldwide. Almost every year, there will be snow disasters in north Xinjiang, northwestern China. Since the accumulated heavy snow in winter season will seriously threaten people's lives, the main object of this study is to produce a potential hazard map for snow avalanche prevention. Taking three snow seasons from November to March of year 2008 to 2010, potential hazard areas were estimated, based on snow volume products and terrain features. Remote sensing (RS) techniques and geographical information system (GIS) based weighted linear combination (WLC) approach were applied, taking into consideration multiple criteria. Snow avalanche risks were analyzed using physical exposure and vulnerability indexes. The analysis indicates that: the areas at high-risk of avalanches are located in the north and south part of the counties of Altay, Bortala and Ili prefectures; the areas at medium-risk of avalanches are found in the certain part of Altay prefecture and Urumqi, Changji, Tacheng prefectures; the avalanche risk is generally low throughout the large area to the certain part of the study area and the region on the border of the eastern north Xinjiang. Overall, the risks of snow avalanche in Altay and Ili prefectures are higher than that other regions; those areas should be allocated correspondingly more salvage materials.
\end{abstract}

\section{Keywords}

Snow Disaster, Remote Sensing, Weighted Linear Combination, North Xinjiang 


\section{Introduction}

Snow avalanches (hereafter also called avalanches) are a natural disaster that has considerable influence on human activities in mountain regions. Snow avalanches are rapid mass movements occurring in snow covered mountain areas all over the world [1]. Almost every year, there will be snow disaster in Xinjiang [2]. Snow avalanche is one of the serious disasters in north Xinjiang, China, with the characteristics of sudden, fast-movement, large destructive and so on. The massive snow accumulation frequently causes disasters such as livestock casualties, traffic jams and other disasters, causing considerable economic loss and serious damage to towns and farms and leading to local people's production and life affected. Over half of precipitation in the study area falls as snow in the cold season (October to April), and over $84 \%$ of precipitation concentrates in the mountains [3]. Therefore, the research on snow avalanche is very critical to general public for snow disaster prevention.

In order to effectively conduct the investigation on this district, it has these conditions: 1) very wide area with a total land area of 39,845,600 ha; 2) areas greatly different in elevation from $1000 \mathrm{~m}$ to 6300 and 3) serve climate conditions depending on the season to reject human access for field survey. Conventional station observation can hardly meet practical demands. Remote sensing (RS) techniques and geographical information system (GIS) can largely improve the effectiveness and efficiency of snow avalanche monitoring. RS technology has advantages such as large-scale, rapid, cyclical, multi-scale, multi-temporal, etc. GIS has the capability to handle the necessary data gathered from various sources. It combines spatial data with quantitate, qualitative, and descriptive information database, which can support a wide range of spatial queries. Many researchers study and investigate the snow avalanche hazard. However, previous studies almost concentrate on Tien Shan Mountains regions. In this study, we focus on whole north Xinjiang area, including Tien Shan Mountains region and Altay Mountains region. Because north Xinjiang, its land area, consists of two large mountain ranges with the basin in between. The problem of living with this natural hazard is known and must be addressed. Moreover, it requires a more detailed description of the avalanche hazard area. Based on comprehensive analysis over current research status at home and abroad and previous studies, this paper aims to produce a potential hazard map for snow avalanche prevention on north Xinjiang, China. RS techniques and a GIS-based weighted linear combination method are put into the research on the establishment of potential avalanche hazard map, on the basis of rules related to topographical characteristics. Avalanche risks were analyzed with physical exposure and vulnerability indexes overlay to the potential hazard map, on the basis of available information.

\section{Study Area and Data Used}

\subsection{Study Area}

The northern part of Xinjiang Uyghur Autonomous Region (hereafter called north Xinjiang) located on northwestern China was selected as a case study area (Figure 1). The extreme minimum temperature may reach $-40^{\circ} \mathrm{C}$ and the mean duration of snow cover is about 130 days per year, generally from the middle of November

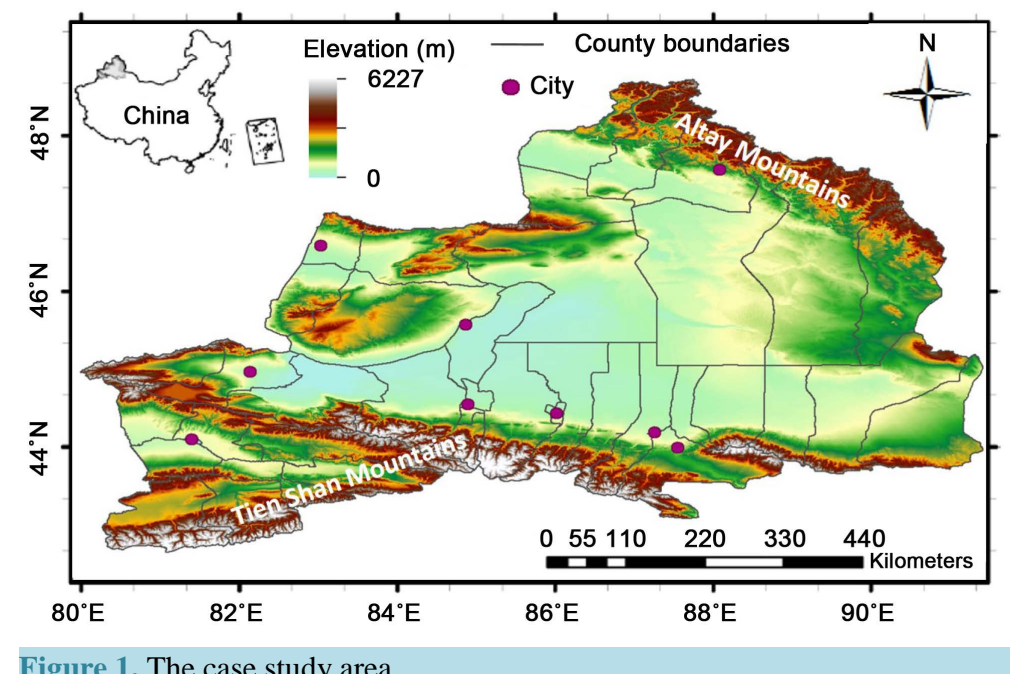

Figure 1. The case study area. 
through March. In particular, northern Xinjiang is one of three snow centers in China. It has a relatively rich seasonal snow source due to winter circulation around the Siberian High and southern mountain blockage. Over half of precipitation in the study area falls as snow in the cold season (November to April), and over $84 \%$ of precipitation concentrates in the mountains [4]. Snow avalanches which are the major threat to lives and property every winter season such as livestock casualties, traffic jams and other disasters over the study area cause considerable economic loss and serious damage to towns and farms.

\subsection{Data Used}

Available remote sensing products exist at a wide variety of spatial and temporal resolutions. The data set used in this research is: 1) The Moderate Resolution Imaging Spectra radiometer (MODIS) Snow Cover 8-day L3 Global $500 \mathrm{~m}$ Grid product. This product has been provided through the Distributed Active Archive Center (DAAC) of the National Snow and Ice Data Center (NSIDC). The data set contains data fields for maximum snow cover extent over an eight-day compositing period and a chronology of snow occurrence observations. The data are based on a snow mapping algorithm that utilize a Normalized Difference Snow Index (NDSI) and two additional criteria tests: the thresholds of Band 2 and Band 4 (http://nsidc.org/data/modis/data_summaries/index.html). 2) The Advanced Microwave Scanning Radiometer-Earth Observing System (AMSR-E) monthly L3 Global Snow Water Equivalent (SWE) product. This product has been available from the Distributed Active Archive Center (DAAC) of the National Snow and Ice Data Center (NSIDC) since June 2002. This product is generated from AMSR-E/Aqua L2A Global Swath Spatially Resampled Brightness Temperatures data. For each low frequency ( $<89 \mathrm{GHz}$ ) sample, snow depth retrieval is performed through snow maps masking and brightness temperatures classifying. And then retrievals and calibrated and projected into $25 \mathrm{~km}$. Equal-Area Scalable Earth Grids (EASE-Grids) (http://nsidc.org/data/amsre/data_summaries/index.html). 3) Canadian Meteorological Centre (CMC) Daily Snow Depth Analysis Data. The data set consists of Northern Hemisphere snow depth analysis data processed by the Canadian Meteorological Center (CMC). Snow depth data obtained from surface synoptic observation (synops), meteorological aviation reports (metars), and special aviation reports (SAs) were acquired from the World Meteorological Organization (WMO) information system for use in the CMC analyses (http://nsidc.org/api/metadata?id=nsidc-0447). 4) The Advanced Space borne Thermal Emission and Reflection Radiometer (ASTER) Global Digital Elevation Model (GDEM) version 2; this product was produced in cooperation with the Japan-US ASTER Science Team using ASTER data (http://asterweb.jpl.nasa.gov/gdem.asp). 5) Statistical data. These profile data obtained from Xinjiang Statistical Yearbook were published by China Statistics Press.

The characteristics of those data used in this research are summarized in Table 1.

\section{Methodology}

The first step is building a hierarchy which can model the problem. Snow volume, altitude, and slope selected as an evaluation factor for potential avalanche danger model, since snow accumulation and steep topography are prerequisites of avalanches. In this study, snow avalanche danger is the decision goal, and snow volume, elevation, and slope are selected as fundamental evaluation factors in the model. GIS has the capability to handle and simulate the necessary data gathered from various sources [5]. GIS combines spatial data with quantitative, qualitative, and descriptive information database, which can support a wide range of spatial queries. All of these

\begin{tabular}{|c|c|c|c|}
\hline Data & Spatial resolution & Tile & Source \\
\hline MODIS & $500 \mathrm{~m}$ & h23v04, h24v04 & NSIDC \\
\hline AMSR-E & $25 \mathrm{~km}$ & & NSIDC \\
\hline Snow depth & $24 \mathrm{~km}$ & & CMC \\
\hline GDEM & $30 \mathrm{~m}$ & N30E70 - N50E100 & USGS \\
\hline Statisctical date & & & \\
\hline
\end{tabular}


factors have made GIS an essential tool for potential hazard area estimation. A multi-criteria evaluation (MCE) method can serve to inventories, classify, analyze and conveniently arrange the available information concerning choice-possibilities in regional planning. It is mainly involved with how to combine the information from several criteria to form a single complex of evaluation. It is used to deal with difficulties that decision makers encounter in handling large amounts of complex information. Weighted linear combination (WLC) is one of the widely used MCE methods for land suitability analysis. WLC is a concept which combines maps by applying a standardized score to each class of a certain parameter and a factor weight to the parameters themselves. It involves standardization of the suitability maps, assigning the weights of relative importance to the suitability's maps, and then combining the weights and standardized suitability maps to obtain an overall suitability score. The WLC analysis was applied using the following equation:

$$
H=\sum \mathrm{W}_{i} \times \mathrm{X}_{i}
$$

where $H$ is the Dangerous degree, $W_{i}$ is a weighting of factor $i$, and $X_{i}$ is the criteria score of factor $i$. In this research, using a GIS-based WLC analysis, examines a major three possible factors for a snow avalanche problem, taking into consideration multiple criteria. In order to use GIS for decide potential snow avalanche hazard area, data were stored in the GIS system and each parameter is considered as layer. To apply the WLC analysis practically, ArcGIS software package were used. ArcGIS software uses a weighted sum analysis that is act as a WLC analysis. A weighted sum analysis provides the ability to weight and combine multiple inputs to create an integrated analysis. In other words, it combines multiple raster inputs, representing multiple factors, of different weights or relative importance. It is one of common methodologies used for snow disaster monitoring in general, and for defining potential hazard area in particular.

\subsection{Produce Snow Volume Product}

Snow avalanche is a falling mass of snow. A large volume of snow is necessary for an avalanche to occur. Snow volume is sum of all non-zero snow depth pixels multiplied by the snow covered area pixel [6]. The biggest problem in analyzing a snow-cover time series is cloud coverage. In practice, it was difficult to find a MODIS image that was no cloud contamination for the Xinjiang area [7]. Clear-sky conditions are rare, especially in the winter season [8].

Figure 2 displays the monthly cloud-cover percentage for four selected years in northern Xinjiang. The maximum cloud coverage is mainly concentrated during winter months (The percentage of cloud coverage mainly concentrated on winter season). The overall mean cloud-cover percentage in winter months varies from $20 \%$ for 2008 , down to $10 \%$ for 2009 , increase to $20 \%$ for 2010 , and over $22 \%$ for 2011 . It significantly limits the ability to map the exact number of snow-covered days. However, when aiming at snow-cover extent analyses over time, a cloud-free time series is a major prerequisite.

Generation of snow volume product mainly consist of following two steps: first, produce cloud-free snowcovered product; then, produce snow volume product. The flowchart for the produce snow volume product is shown in Figure 3. Optical sensors such as MODIS have high classification accuracy in clear-sky condition while it is much lower if cloud is counted. Space-borne passive microwave data, such as the AMSR-E data, has

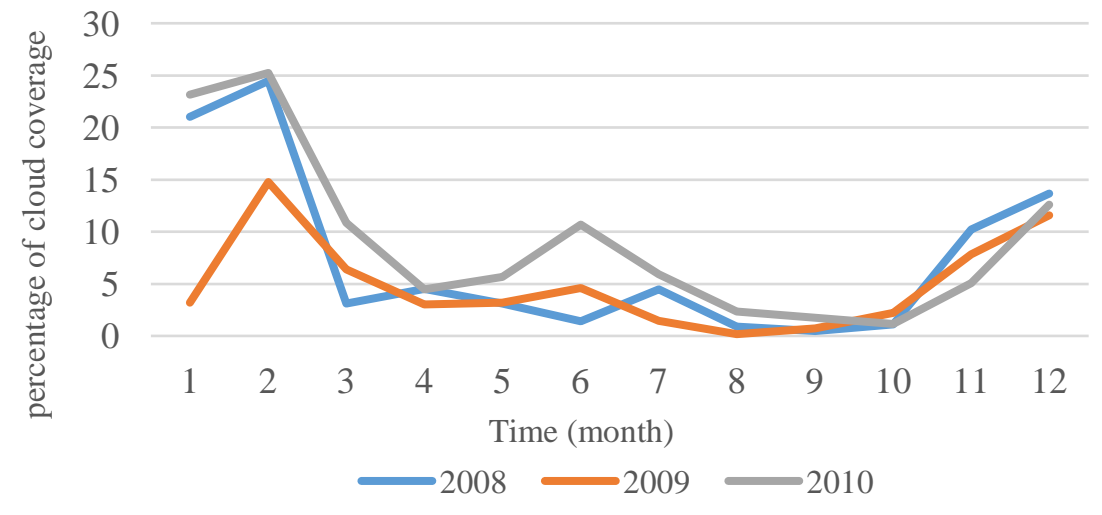

Figure 2. The state of cloud coverage in north Xinjiang. 


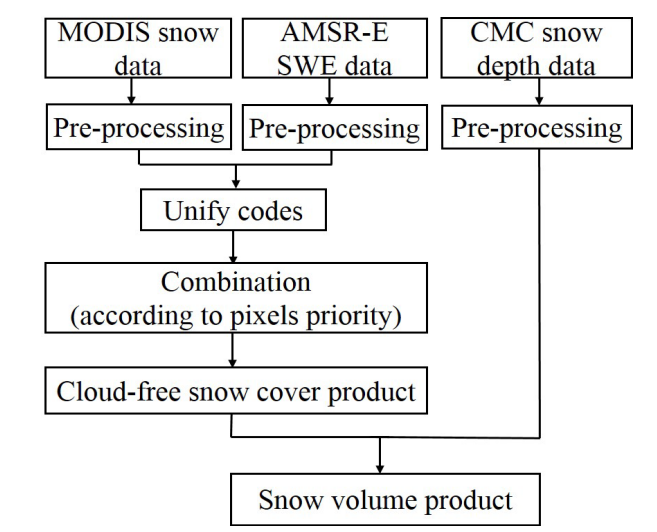

Figure 3. Flowchart for produce snow volume product.

the advantage of all-weather imaging but a much coarse resolution. The algorithm which for merging two remote sensing products (utilizing MODIS snow cover products and AMSR-E SWE products) with complementary spatiotemporal resolution characteristics is taken to generate cloud-free snow cover products, similar to Gao et al. (2010) [9]. A method consists of unifying codes, combing products. 1) Unifying codes: The original integer numbers in the MODIS and AMSR-E products were then transformed to new codes and used for the combination processes. 2) Combining products: replace the remaining cloud or other contamination of MODIS using the value of AMSR-E Snow Cover image. According to the definition of snow volume, snow volume product generated from multiplication of cloud-free snow-covered area with snow depth.

\subsection{Define Potential Hazard Area}

Potential hazard map is produced through spatial data process operation (Figure 4). For each evaluation factor, reclassification system is required. Moreover, overly calculation over all of evaluation factors' data need to be executed so that the score of each study unit's snow avalanche danger could be calculated and then danger grade could be made according to operation system. Detail explanation about the step that how to perform weighted sum analysis are:

1) All three input data were given scores to reclassify. Since these three input layers are in different numbering systems and with different ranges, raster's of these data could not be simply added. For each factor, reclassification system is required. The score assess their importance on snow avalanche occurrence on study area that range from 0 to 10 (Table 2). The higher score was obtained, the more importance it would present. A score of 0 indicates no potential danger, and a score of 10 indicates an extremely serious dangers. The total values with the higher scores will represent the events most in need of organization planning for emergency preparedness. In this study, the criteria for slope and altitude in selected parameters based on the local condition of study area, the criteria for slope from the method of [10]. They were proceeded map overlaying analyses in GIS for the values of grids. This method can provide the decision makers several options for selecting appropriate strategies, since using this method, the final output map will range from the "high dangerous" to "no dangerous".

2) Identify weights for these three input data. Evaluation factors in the model may have different importance. Before the factors are combined the factors can be weighted, based on their importance (Table 2). Weights were generally assigned to these maps to express the relative importance. The total weight should be added up to $100 \%$ in order for the output map to be meaningful and consistent, and the attribute score must be chosen using a scheme that was the same for each map. As a general rule, it was decided to give higher weightings to factors that affect directly on the community. In this study, the three selected evaluation factors are considered as almost equal important in pair-wise comparison.

Then, a final composite map was produced using WLC. The cell values of each input raster are multiplied by the raster's weight. The resulting cell value is added to produce the final output raster. Based on current understanding for study area's snow avalanche occurrence mechanism, the layers, the criteria, the reclassification system and their weights are listed (summarized) in Table 2. 


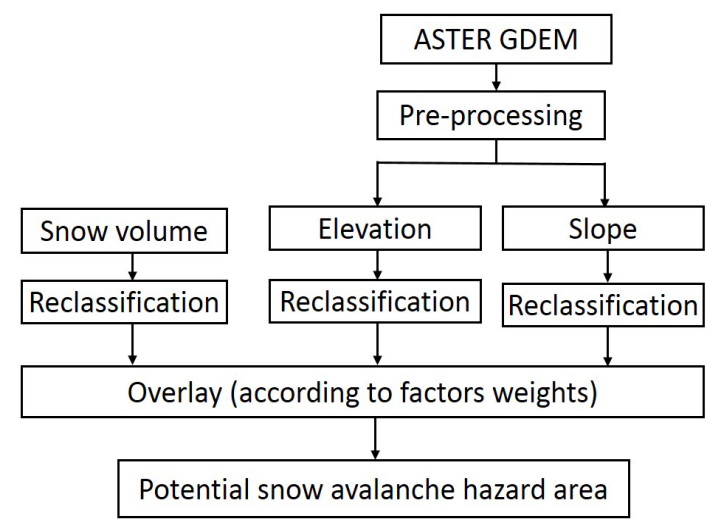

Figure 4. Spatial data process operation for define potential hazard area in north Xinjiang.

Table 2. Attribute scores and weights for the map used in the avalanche hazard decision.

\begin{tabular}{cccc}
\hline Category & Spatial resolution & Score & Weights \\
\hline \multirow{2}{*}{ Snow volume } & $2500<\mathrm{V}$ & 1 & \\
& $5000<\mathrm{V}<\mathrm{V}<\mathrm{r} 000$ & 4 & 0.4 \\
& $7500<\mathrm{V}$ & 7 & \\
& $1<\mathrm{H}<1000$ & 10 & \\
Altitude & 4 & 7 & 0.3 \\
& $3500<\mathrm{H}$ & 10 & \\
Slope & $\alpha<30$ & 4 & \\
& $30<\alpha<40$ & 7 & 0.3 \\
& $40<\alpha$ & 10 & \\
\hline
\end{tabular}

\section{Experimental Results and Discussion}

\subsection{Comparison of MODIS Snow Products with Cloud-Free Snow Cover Products}

Figure 5 shows comparison between MODIS snow products and cloud-free snow cover products on monthly time scales. $\mathrm{X}$ axis indicate time (month) scale, $\mathrm{Y}$ axis indicate percentage of each factor. By taking advantage of both high spatial resolution of optical data and cloud transparency of passive microwave data, the combination of MODIS and AMSR-E removed all the cloud and other contaminations, greatly complements the deficiency of MODIS product. This process proves that produce cloud-free snow cover product by merging existing MODIS and AMSRE Snow product is practicable. The results shows that the new monthly cloud-free snow cover product at $500 \mathrm{~m}$ resolution can effectively capture snow covered information during January 2008 to December 2010.

\subsection{Dynamics of Snow Volume}

Outputs presents that the total snow volume of 2008 and 2009 is lower than the total snow volume of 2010 (Figure 6). The time variation of the snow volume is almost dominated by the seasonal cycle. Results show that the mean annual snow volume over the whole study is domain equal to (48) $\mathrm{km}^{3}$, (60) $\mathrm{km}^{3}$, and (89) $\mathrm{km}^{3}$ over this three year time period, respectively. The mean monthly snow volume ranges from about $38 \times 10^{9} \mathrm{~m}^{3}$ in summer to about $104 \times 10^{9} \mathrm{~m}^{3}$ in winter. The serious snow volume from December to March, accounted for $80 \%$ of the total snow volume. From November to March, snow volume was increasing (this season called snow accumulation season), this heavy snow accumulation leads to snow disasters, such as snow avalanches, snow drifting, etc. From March to June, snow volume was decreasing (this season called snow melting season), this type serious snow melting may occurred floods, name as snow-melt flood. In addition, serious snow volume change mainly concentrated on Altay, Tacheng, and Ili regions. The monthly variation of snow volume time series over the study area during January 2008 and December 2010 are shown Figures 7-9. 

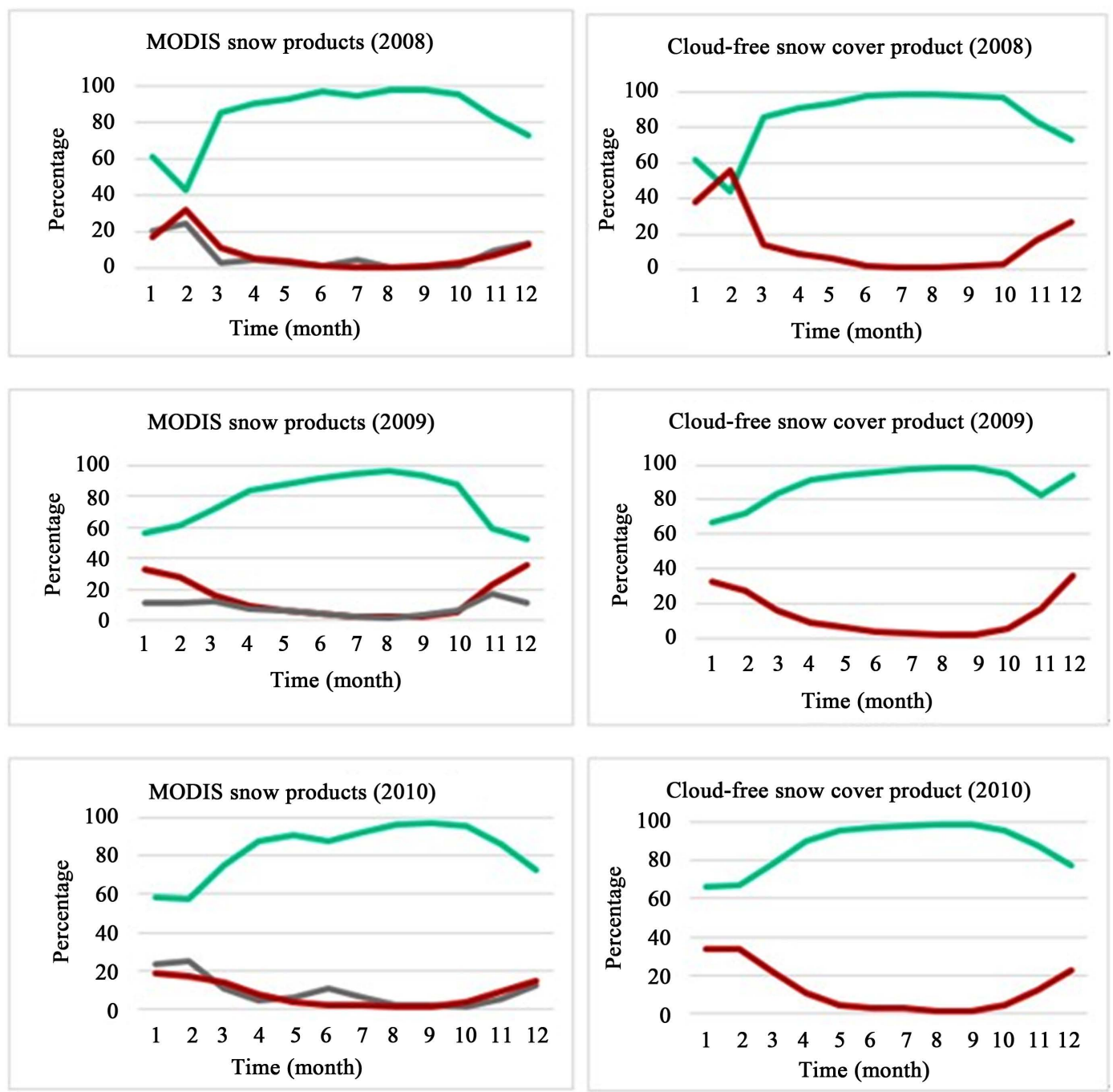

Figure 5. Comparison of MODIS snow products with cloud-free snow cover products (red line shows snow; green line shows non-snow; grey line shows cloud).

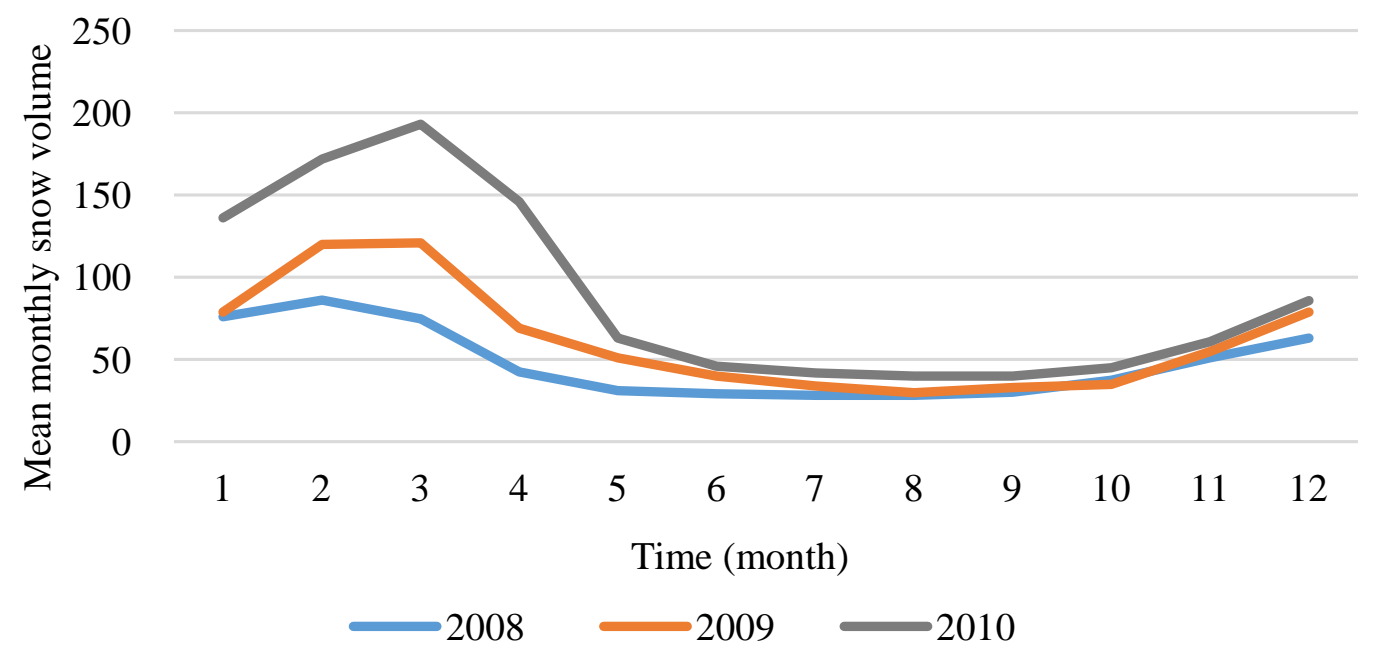

Figure 6. The state of mean monthly snow volume variation. 


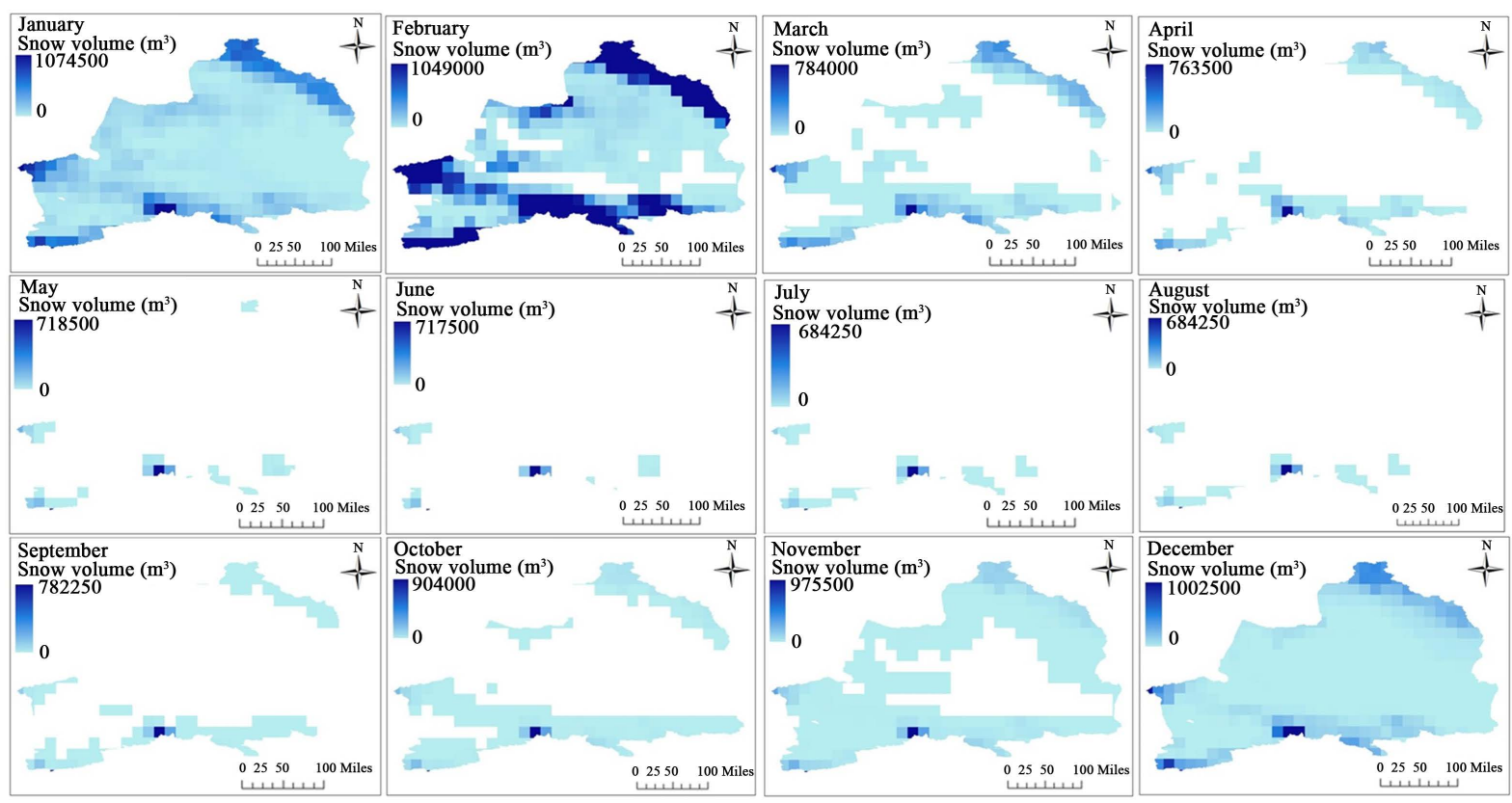

Figure 7. The mean monthly snow volume variation (2008).

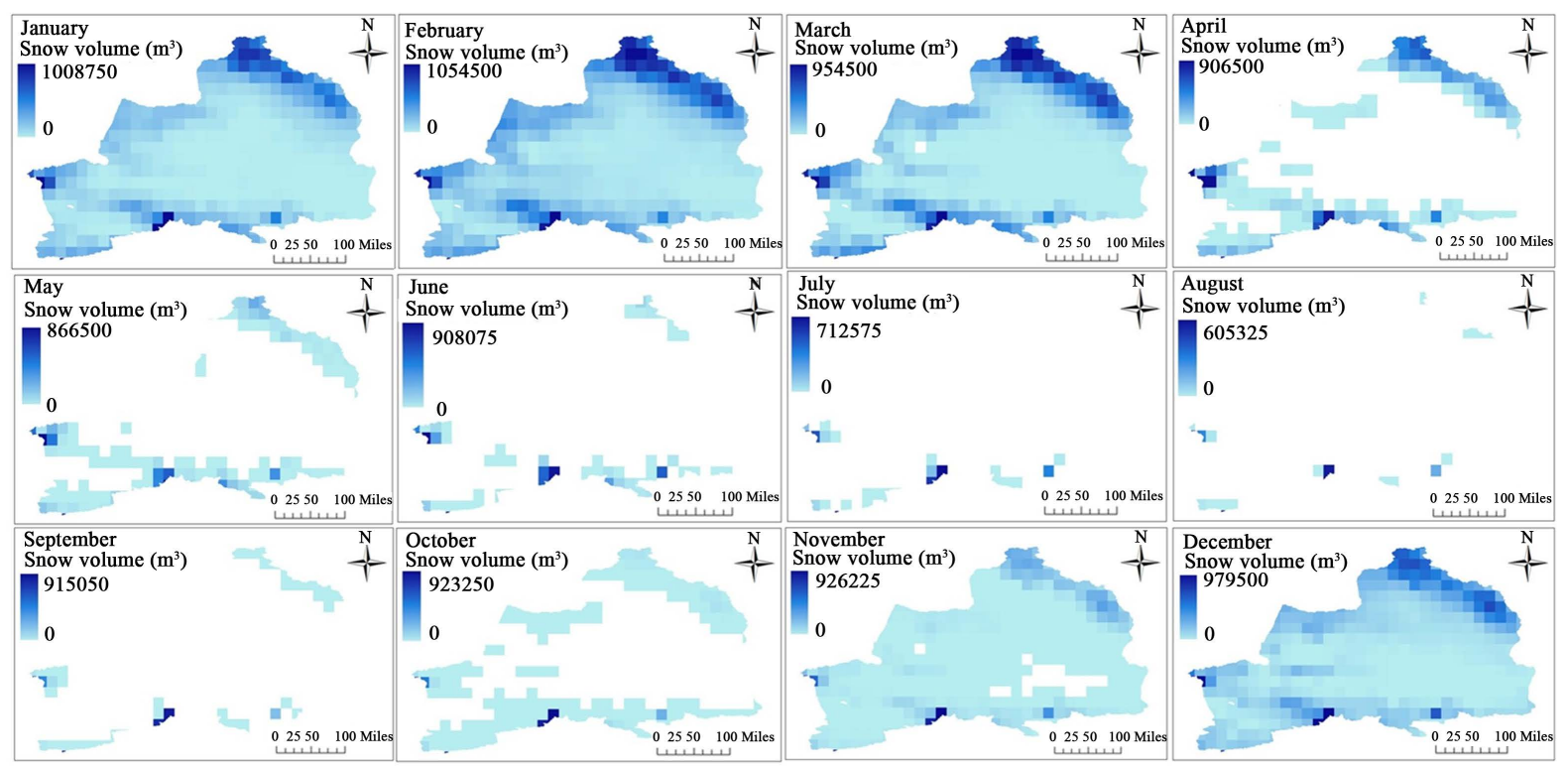

Figure 8. The mean monthly snow volume variation (2009).

From November to March, snow volume was increasing (this season called snow accumulation season), this heavy snow accumulation leads to snow disasters, such as snow avalanches, snow drifting, etc. From March to June, snow volume was decreasing (this season called snow melting season), this type serious snow melting may occurred floods, name as snow-melt flood.

\subsection{Potential Avalanche Hazard Map}

The resulting potential hazard map for snow avalanche prevention was shown in Figure 10. The dangerous grade for potential hazard map were named: no danger (zone I), very low danger (zone II), moderate danger (zone III), high danger (zone IV), and very high danger (zone V). As shown in Figure 10, the areas threatened by very high and high of potential snow avalanche hazard are located in the five counties of Habahe (Kaba), Bur- 


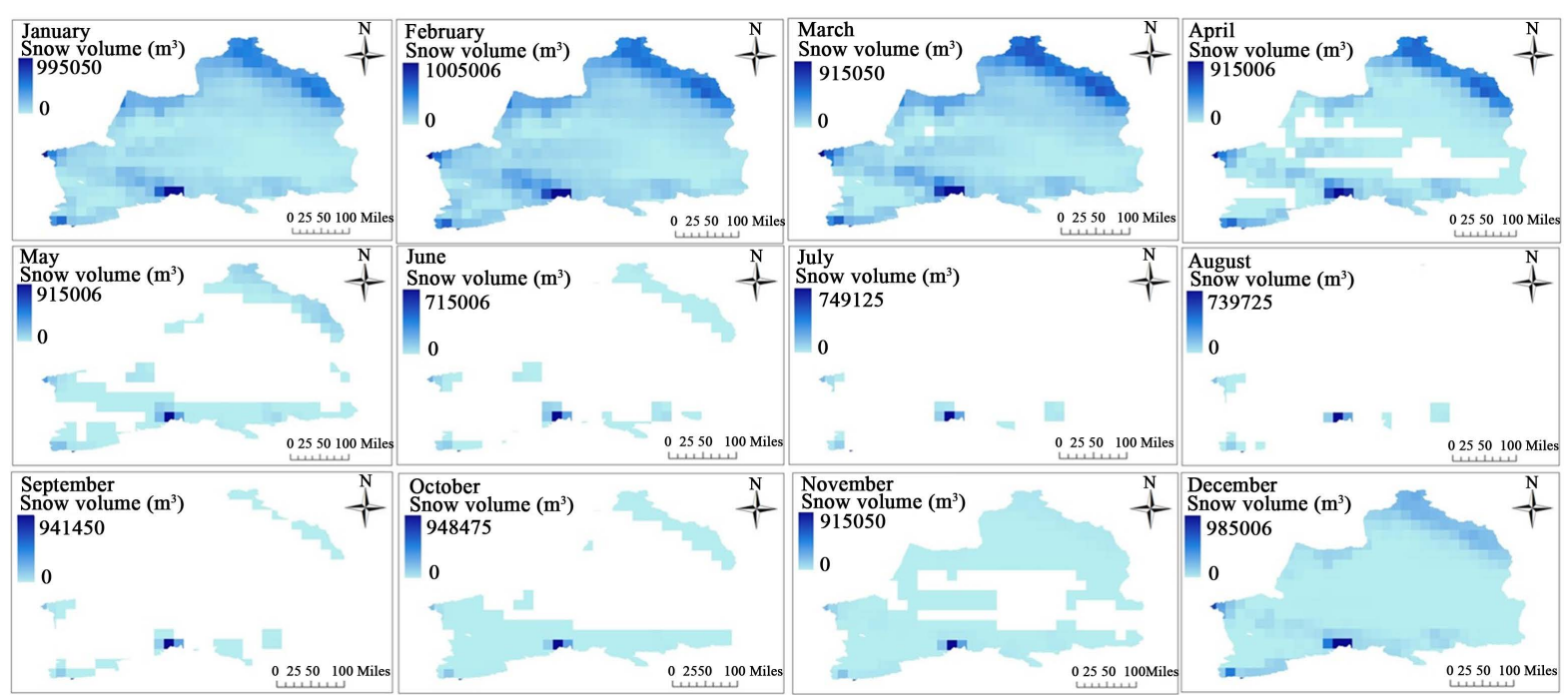

Figure 9. The mean monthly snow volume variation (2010).

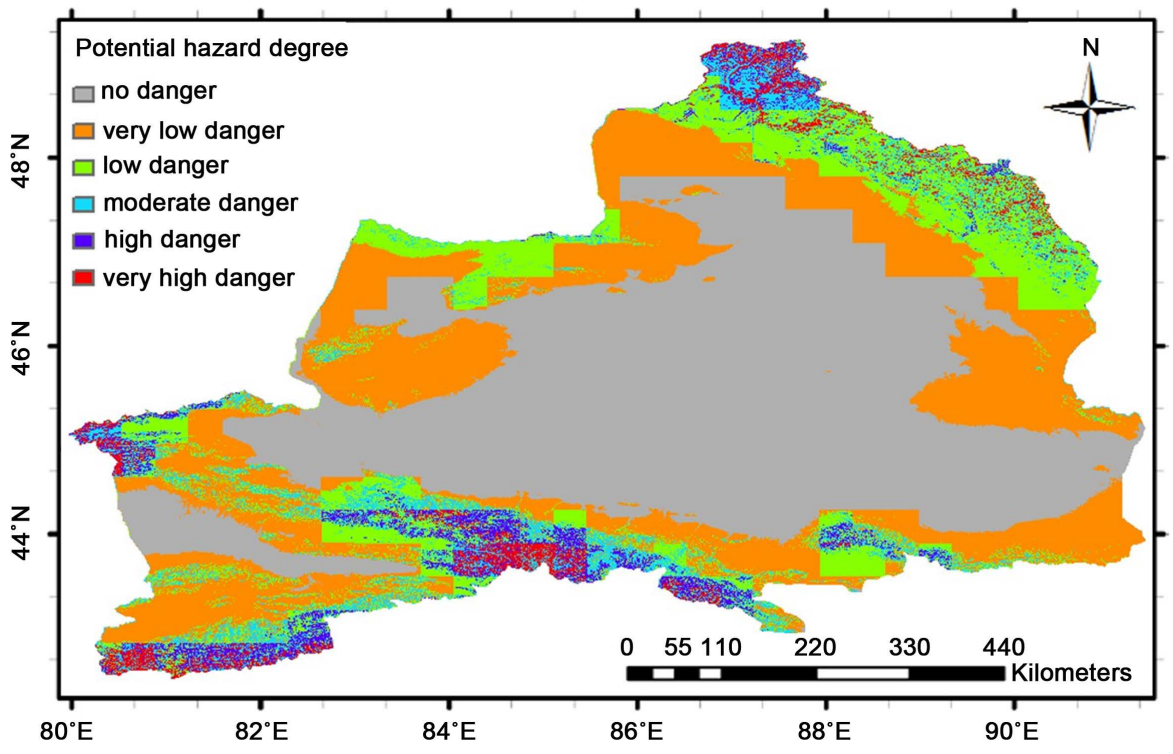

Figure 10. Potential hazard map for snow avalanche prevention in north Xinjiang.

qin, Zhaosu (Mongolkure), Tekas, and Nilka, which are located in the north section of Altay mountains and in the south and east section of Tien Shan Mountains. In these areas, the number of days with snow cover every year can exceed 200, with the longest snowfall period, beginning earlier and ending later than in other regions. During the period from November to April, the areas covered with permanent snow are more susceptible to snow disaster.

Areas at moderate danger of potential snow avalanche hazard are found the following 13 counties: Altay, Fuhai, Fuyun, Qinghe, Wenquan, Hupcheng, Xinyuan, Usu, Shawan, Changji, Fukang, Jimisar, Hutubi, which are scattered across the Altay prefecture in the north, Tacheng, Bortala and Ili prefectures in west and Changji prefecture in the south. These areas cover at elevations from $1000 \mathrm{~m}$ to $3500 \mathrm{~m}$. The danger of potential snow avalanche hazard is generally low throughout the area in Qitai, MoriKazak, Manas, Xinyuan, Qapqal, Bole, Jinghe, Yumin, Tuoli, Tacheng, Emin, and jeminay, which are located on the east part of Altay prefecture, middle of Ili prefecture, and Tacheng prefecture. The dangerous free area of potential hazard includes Junggar basin and its surroundings. Overall, the relative high dangerous areas of potential snow avalanche hazard area founded in Ili prefecture in the south, and Altay prefecture in the north than other regions. 


\section{Risk Analysis in North Xinjiang}

In the 1990s, scholars recognized that natural disasters had both natural and social attributes [11]. As mentioned in the previous section, the number of natural disasters has been increasing, as has their impact, due to such external changes as the concentration of populations and property in hazardous areas. Snow avalanche, torrential rains, earthquakes, are natural phenomena we refer to as "hazards" and are not considered to be disasters in and of themselves. For instance, a snow avalanche that occurs on a top of alpine does not trigger a disaster because there is no existing population or property affected. In addition to a hazard, some "vulnerability" to the natural phenomenon must be present for an event to constitute a natural disaster. "Vulnerability" is defined as a condition resulting from physical, social, economic, and environmental factors or processes, which increases the susceptibility of a community to the impact of a hazard. "Exposure" is another component of disaster risk, and refers to that which is affected by natural disasters, such as people and property. In general, "risk" is defined as the expectation value of losses (deaths, injuries, property, etc.) that would be caused by a hazard. Disaster risk can be seen as a function of the hazard, exposure and vulnerability as follows:

$$
\text { Disaster Risk = function (Hazard, Exposure, Vulnerability) }
$$

Growing exposure and delays in reducing vulnerabilities result in an increased number of natural disasters and greater levels of loss. In present paper, snow avalanche risk were analyzed using physical exposure and vulnerability indexes, which including population density, livestock number at the end of year, and highway network (Figure 11). They reflect the risk assessment of snow avalanches on the north Xinjiang.

The snow avalanche risk analysis revealed that: the areas at high-risk of snow avalanche on the north Xinjiang area are mainly located in north and south part of the counties of Altay, Bortala and Ili prefectures. These areas influenced by northern cold air. With the longest snow fall period, in these areas, the number of snow covered days can exceed 200, beginning earlier and ending later than in other region. During the period from November to April, these areas covered with permanent snow are more susceptible to snow avalanches. The areas at medium-risk of snow avalanches are found in certain part of Altay prefecture, Urumqi, Changji, and Tacheng prefectures. These areas cover at elevation from $1000 \mathrm{~m}$ to $3500 \mathrm{~m}$. The risk of snow avalanches is generally low throughout the large area to the certain part of study area and the region on the border of the eastern north Xinjiang. Overall, the avalanche risk of snow disaster in Altay and Ili prefectures are higher than that other regions. This study suggests that those areas should be allocated correspondingly more salvage materials. To reduce snow disaster risk, it is important to reduce the level of vulnerability and to keep exposure as far away from hazards as possible by relocating populations and property. The reduction of vulnerability can be achieved through such measures as mitigation and preparedness.

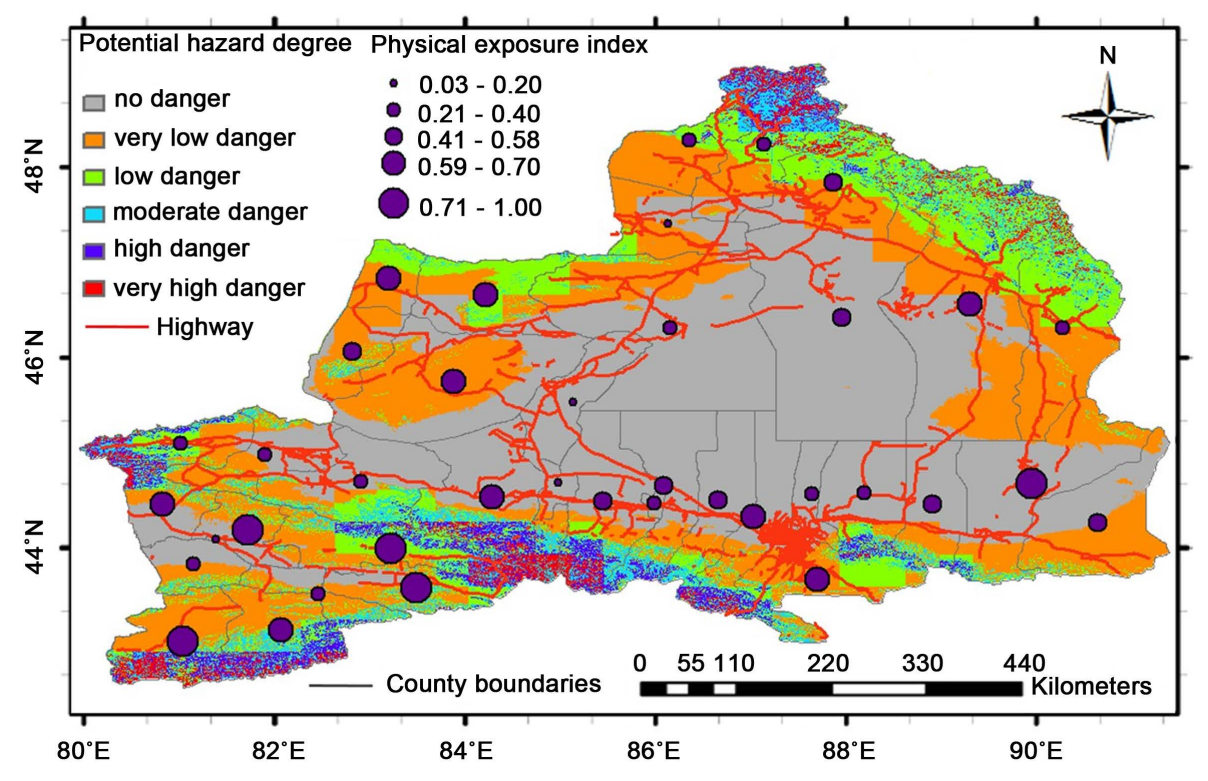

Figure 11. Snow avalanche analysis for north Xinjiang area. 


\section{Summary}

The north Xinjiang is a region of China that frequently experiences snow avalanche disaster, which affects people's lives and productivity, causing serious damage to towns and farms. An accurate definition of the potential hazard area and the assessment of snow avalanche risk are important if the hazard of snow disaster is to be mitigated. With the help of avalanche theories formulated in China and abroad, the final target of this study has been achieved in terms of the potential hazard map for snow avalanche prevention. The theoretical framework of snow avalanche disaster risk is described, which has a guide meaning in snow avalanche disaster mitigation. An index of physical exposure and vulnerability, including population density and livestock number at the end of year, highway network, is established based on the data from Xinjiang statistical yearbook. They reflect the risk assessment of snow avalanches on the north Xinjiang. The need has been established for better analysis, communication, and visualization of avalanche hazard to aid decision-making. The conclusions of this study are as follows: 1) Using RS techniques and GIS-based weighted linear combination method to scientifically map potential avalanche dangerous area for snow avalanche prevention, based on snow volume product and terrain features, over 2008 to 2010 for north Xinjiang area and visualize the results. According to the results, we could obtain information for disaster management. For example, we could obtain the danger level of each region. The methods have certain advantages, such as having simple processes and providing quantitative, comparative, synthetic, analytic results. 2) Snow volume products were calculated from generated cloud-free snow covered product and existing snow depth data. In order to obtain cloud free snow covered data, MODIS snow covered data and AMSR-E data were merged, since, in practice it was difficult to find a satellite image that was no cloud contamination for the Xinjiang area. Positive combination of both MODIS snow covered data and AMSR-E SWE data, removed the all cloud area of MODIS data. Snow volume product will be the first snow volume product in the north Xinjiang area, and this study provides accurate snow volume information temporally and spatially. 3) The snow avalanche risk analysis revealed that: the areas at high-risk of snow avalanche on the north Xinjiang area mainly located in the north and south part of the counties of Altay, Bortala and Ili prefectures. These areas are influenced by the northern cold air. With the longest snow fall period, in these areas, the number of snow covered days can exceed 200, beginning earlier and ending later than in other regions. During the period from November to April, these areas covered with permanent snow are more susceptible to snow avalanches. The areas at medium-risk of snow avalanches are found in the certain part of Altay prefecture, Urumqi, Changji, and Tacheng prefectures. In this area, coverages are at elevation from $1000 \mathrm{~m}$ to $3500 \mathrm{~m}$. The risk of snow avalanches is generally low throughout the large area to the certain part of the study area and the region on the border of the eastern north Xinjiang. Overall, the avalanche risk of snow disaster in Altay and Ili prefectures is higher than the other regions. This study suggests that those areas should be correspondingly allocated more salvage materials. The potential hazard map and avalanche risk analysis in this study are specifically intended to support the local government and native people in the future, and hope to play a role in the prevention of snow avalanches. Future effort is required to more advanced data acquisition techniques which should be introduced into the monitoring model.

\section{Acknowledgements}

The authors would like to appreciate the Distributed Active Archive Center (DAAC) of National Snow and Ice Data Center (NSIDC), Canadian Meteorological Centre (CMC), and US Geological Survey (USGS) for providing the free products to support kinds of remote sensing researches.

\section{References}

[1] Eckerstorfer, M. (2012) Snow Avalanche in Central Svalbard: A Field Study of Meteorological and Topographical Triggering Factors and Geomorphological Significance. Ph.D. Thesis, University of Oslo, Oslo.

[2] Su, W., Zhang, X., Wang, Z., Su, X., Huang, J., Yang, S. and Liu, S. (2011) Analyzing Disaster Forming Environments and the Spatial Distribution of Flood Disasters and Snow Disasters that Occurred in China from 1949 to 2000. Mathematical and Computer Modelling, 54, 1069-1078. http://dx.doi.org/10.1016/j.mcm.2010.11.037

[3] Sun, G., Chen, Y., Li, W., Pan, C., Li, J. and Yang, Y. (2013) Spatial Distribution of the Extreme Hydrological Events in Xinjiang, North-West China. Natural Hazards, 67, 483-495. http://dx.doi.org/10.1007/s11069-013-0574-5

[4] Wang, X., Xie, H. and Liang, T. (2007) Evaluation of MODIS Snow Cover and Cloud Mask and Its Application in 
Northern Xinjiang, China. Remote Sensing of Environment, 10, 1-17. http://dx.doi.org/10.1016/j.rse.2007.05.016

[5] Al-Hanbali, A., Alsaaideh, B. and Kondoh, A. (2011) Using GIS-Based Weighted Linear Combination Analysis and Remote Sensing Techniques to Select Optimum Solid Waste Disposal Sites within Mafraq City, Jordan. Journal of Geographic Information System, 3, 1-12. http://dx.doi.org/10.4236/jgis.2011.34023

[6] Sylvain, B., Anny, C., Nelly, M. M., William, L. and Frédéric, F. (2011) Satellite-Based High Latitude Snow Volume Trend, Variability and Contribution to Sea Level over 1989/2006. Global and Planetary Change, 75, 99-107. http://dx.doi.org/10.1016/j.gloplacha.2010.10.011

[7] Liang, T., Zhang, X., Xie, H., Wu, C., Feng, Q., Huang, X. and Chen, Q. (2008) Toward Improvely Daily Snow Cover Mapping with Advanced Combination of MODIS and AMSR-E Measurement. Remote Sensing Environment, 112, 3750-3761. http://dx.doi.org/10.1016/j.rse.2008.05.010

[8] Dietza, A.J., Kuenzera, C. and Conrad, C. (2013) Snow-Cover Variability in Central Asia between 2000 and 2011 Derived from Improved MODIS Daily Snow-Cover Products. International Journal of Remote Sensing, 34, 3879-3902. http://dx.doi.org/10.1080/01431161.2013.767480

[9] Gao, Y., Xie, H., Lu, N., Yao, T. and Liang, T. (2010) Toward Advanced Daily Cloud-Free Snow Cover and Snow Water Equivalent Products Deom Terra-Aqua MODIS and Aqua AMSR-E Measurements. Journal of Hydrology, 385, 23-35. http://dx.doi.org/10.1016/j.jhydrol.2010.01.022

[10] Liu, X., Liu, Y., Li, L. and Ren, Y. (2009) Disaster Monitoring and Early-Warning System for Snow Avalanche along Tianshan Highway. IGRARSS, II-634-637.

[11] Liu, F., Mao, X., Zhang, Y., Chen, Q., Liu, P. and Zhao, Z. (2014) Risk Analysis of Snow Disaster in the Pastoral Areas of the Qinghai-Tibet Plateau. Journal of Geographical Science, 24, 411-426. http://dx.doi.org/10.1007/s11442-014-1097-z 
Scientific Research Publishing (SCIRP) is one of the largest Open Access journal publishers. It is currently publishing more than 200 open access, online, peer-reviewed journals covering a wide range of academic disciplines. SCIRP serves the worldwide academic communities and contributes to the progress and application of science with its publication.

Other selected journals from SCIRP are listed as below. Submit your manuscript to us via either submit@scirp.org or Online Submission Portal.
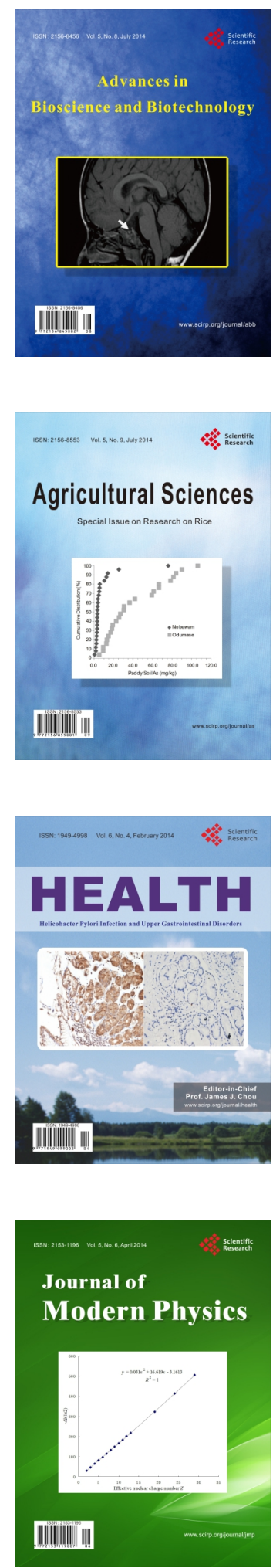
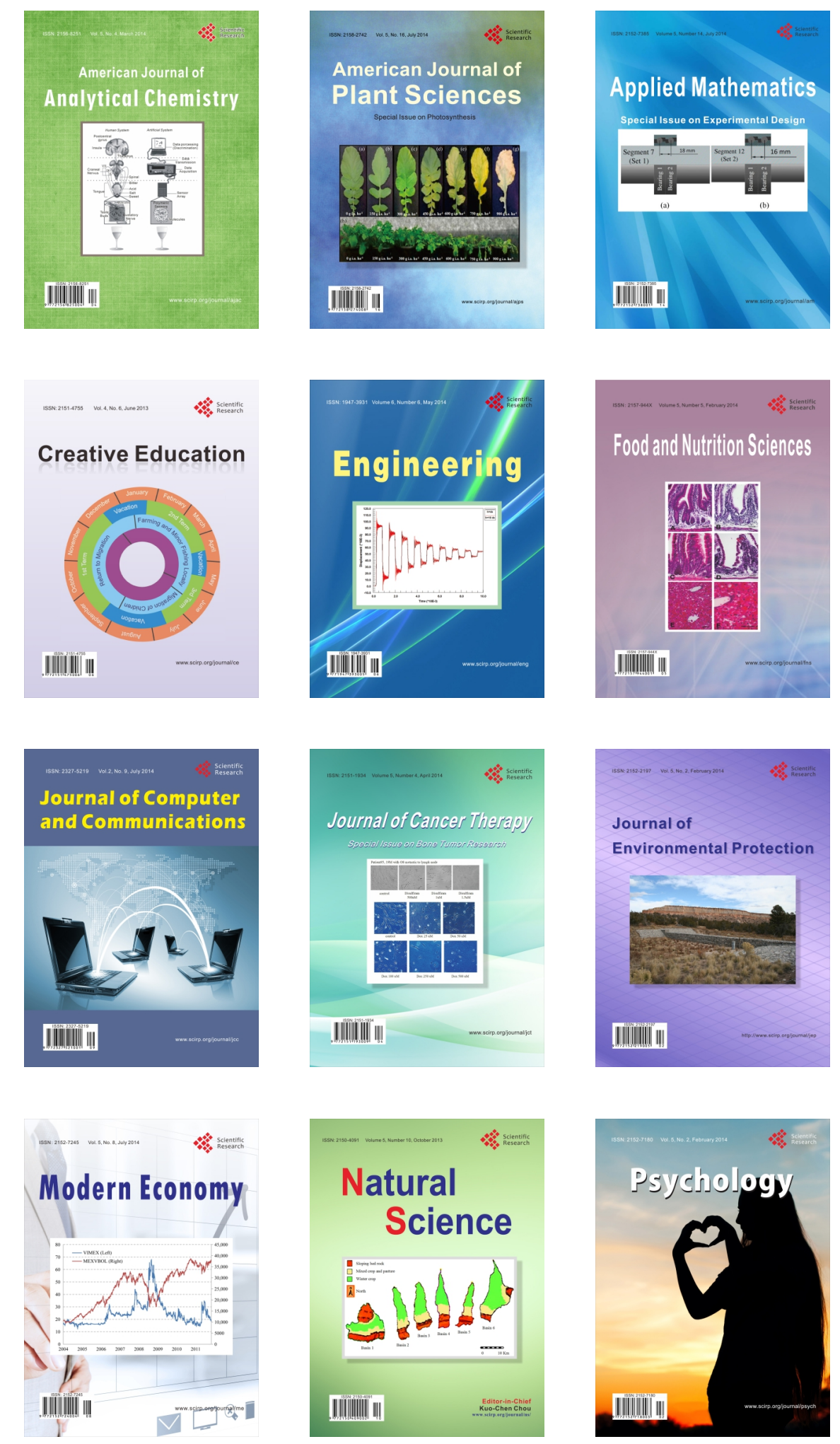